\title{
EDITORIAL
}

\section{Benefits of Purely Online Journals and the Challenges}

\author{
Shaukat Ali Jawaid ', Masood Jawaid ${ }^{2}$ \\ ${ }^{1}$ Chief Editor, Pakistan Journal of Medical Sciences, ${ }^{2}$ Associate Editor, Pakistan Journal of Medical Sciences, Karachi, Pakistan. \\ https://doi.org/10.36283/PJMD10-4/001
}

There are numerous well-established parameters to judge and evaluate the standard of a medical journal like quality of its contents and geographic distribution of manuscripts, it attracts for publication, indexation and coverage in important indexes and databases like Medline, Web of Sciences by Clarivate known for its Impact Factor (IF), PubMed Central, Scopus etc., journal visibility and readership, timely regular publication. Impact Factor is one of the criteria and not the only criteria, which should be used to judge the standard of a journal. However, too much importance being given to the Impact Factor by the regulatory bodies in Pakistan as well as by medical institutions, asking those doing PhD to publish their research work in Impact Factor journals has created a crisis like situation not only for the researchers but also made the life of the IF journal editors miserable. They are under tremendous pressure to accommodate more and more papers by the authors anxious for early publication to meet certain deadlines for the completion of their research project and award of degrees while the editors on their part are faced with a dilemma due to human resource and financial resource constraints. In an environment where political stability remains in short supply most of the time, law and order situation is unpredictable, not to forget the frequent breakdown of electricity and inefficient internet service, it is not possible to either increase the frequency of publications or plan some other measures which all call for additional investment. Finding trained human resource and then retaining those remains a constant problem.

At present, there are only three medical journals in Pakistan, which enjoy Impact Factor (Table 1), and all of them are overwhelmed with submissions, as the authors are keen to get their research published in IF Journals. However, the editors are not in a position to accommodate everyone despite the fact that many of the studies being declined submission or refused further processing are of a very good or reasonable standard. The situation can be very well imagined from the fact that we in the Pakistan Journal of Medical Sciences have already published November - December 2021 issue and the contents of next two issues till April 2022 have also been finalized. After completing the various formalities, now its page make up is in progress so that PDF files could be sent to the authors for proofreading before final publication. Hence all new submissions which are being accepted for further processing are being given the publication date of May - June 2022 as we will not be able to accommodate any newly approved submission during the current year 2021. Since we do not wish to keep the authors waiting for too long, they are being advised to submit their papers to some other journal but it earns a lot of hostile comments and remarks from the authors who simply have no idea under what stressful and frustrating environment the editors have to work.

Table 1: Impact Factor of Pakistani Medical Journals.

\begin{tabular}{|c|l|c|c|c|}
\hline Rank & \multicolumn{1}{|c|}{ Full Journal Title } & Total Cites & Journal Impact Factor & $\begin{array}{c}\text { Eigen Factor } \\
\text { Score }\end{array}$ \\
\hline 1 & Pakistan Veterinary Journal & 1,357 & 1.318 & 0.000840 \\
\hline 2 & Pakistan Journal of Medical Sciences & $\mathbf{3 , 5 1 0}$ & $\mathbf{1 . 0 8 8}$ & $\mathbf{0 . 0 0 4 2 2 0}$ \\
\hline 3 & Pakistan Journal of Botany & 5,830 & 0.972 & 0.002270 \\
\hline 4 & Pakistan Journal of Zoology & 2,169 & 0.831 & $\mathbf{0 . 0 0 1 7 0 0}$ \\
\hline 5 & $\begin{array}{l}\text { Journal of the Pakistan Medical } \\
\text { Association }\end{array}$ & $\mathbf{4 , 3 6 0}$ & $\mathbf{0 . 7 8 1}$ & 0.001020 \\
\hline 6 & $\begin{array}{l}\text { International Journal of } \\
\text { Pharmacology }\end{array}$ & 1,386 & 0.751 & 0.000850 \\
\hline 7 & $\begin{array}{l}\text { Pakistan Journal of Agricultural } \\
\text { Sciences }\end{array}$ & 1,277 & 0.748 & $\mathbf{0 . 0 0 2 3 4 0}$ \\
\hline 8 & $\begin{array}{l}\text { Journal of the College of Physicians } \\
\text { and Surgeons Pakistan }\end{array}$ & $\mathbf{2 , 3 6 7}$ & $\mathbf{0 . 7 1 1}$ & 0.002350 \\
\hline 9 & $\begin{array}{l}\text { Pakistan Journal of Pharmaceutical } \\
\text { Sciences }\end{array}$ & 2,748 & 0.684 & 0.000530 \\
\hline 10 & $\begin{array}{l}\text { Journal of the Chemical Society of } \\
\text { Pakistan }\end{array}$ & 1,122 & 0.536 & 0.001590 \\
\hline 11 & Journal of Animal and Plant Sciences & 2,015 & 0.490 & \\
\hline
\end{tabular}

Source: Journal Citation Report by Clarivate Analytics issued in June 2021 
Therefore, what is the solution? We believe first of all the regulatory bodies should have helped more Pakistani medical journals to get Impact Factor which unfortunately they have not before making it mandatory for researchers pursuing higher postgraduate degrees to publish their work in IF journals. They can select and recognize a few more journals from Pakistan which though at present do not enjoy IF, have already applied for it and have been accepted and included in Emerging Sources Citation Index (ESCI) before they ultimately get included in Science Citation Index Expanded (SCIE) and earn an Impact Factor.

Secondly, the regulatory bodies including HEC should give serious thought to allow Purely Online Journals to those publications, which are covered by important Indexes like Medline and Web of Sciences besides international databases like PubMed Central, Scopus etc. In addition, these journals must be offering Digital Object Identifier (DOI) number to all the manuscripts they publish, which ensures their inclusion in Repository. These journals should be evaluated every two years not every year, as it is a very cumbersome time consuming process. These purely Online Journals will offer many benefits to not only the publishers but also the authors like:

1. Reduction in cost of production (print copy will not be needed)

2. Timely regular publication

3. Increasing the frequency of publication

4. Accommodation of lengthy manuscripts

5. More manuscripts can be published in an issue

6. Publications cost will also be reduced for the authors as the publishers will save the cost on paper and printing which they should pass it on to the authors as well.

Let us take full benefit and advantages of advances the information technology offers and use it for the benefit of authors. The publishers and editors of these IF journals will be able to accommodate more papers as there will be no page constraints. However, it must be mentioned that though publishing purely online journals are less expensive to publish but still there are significant costs involved. In view of the fewer sources of revenue, setting up the basic infrastructure to host, review the papers, editing the manuscripts, formatting issues are all substantially costly. The first open access online journal, Dermatology Online Journal published its first issue in $1915^{\prime}$. Since then the number of Open Access Online journals has increased into thousands and many of them are purely Online Journals and they get due recognition by regulatory bodies in many countries of the world.

However, there are certain challenges with purely Online Journals and this issue of credibility has become all the more important in view of mushroom growth of Predatory Journals, which solicit papers, charge high fees with extremely low oversight. Since publication, charges by some of the well reputed international online journals are very high ranging from one thousand US dollars to four thousand US Dollars, many researchers particularly the young ones easily get trapped by these predatory journals since they are also under pressure to publish their research work. In fact, pressure on the academia to publish timely has resulted in the increased number of predatory journals. On the other hand, usage of print journals has also considerably decreased. The libraries have no place to stock them; many no more accept print copies and users also prefer to use online journals. It is presumed that the availability of online access to full text journals will have even greater impact on collection of print journals in the days to come ${ }^{2}$. In the past before the advent of online journals, authors eagerly awaited the receipt of print copy of the journal containing their manuscripts. Contents could not be changed once the issue was printed and any change had to be in the form of Retraction or Correction in future issue but all these problems have now been resolved with the advent of online journals ${ }^{3}$.

In the Low Middle Income Countries (LMICs), not many medical journals could survive for long due to various reasons. It included lack of funding, irregular publication schedule, weak peer review mechanism that lacked credibility in addition to poor visibility locally as well as globally. This situation emerged since biomedical journals were not given due importance by the policy makers in governments and academia in addition to lack of opportunities for career development and academic progression. Medical institutions, professional societies, publish most journals in these countries. They suffer from lack of staffing as most doctors work on voluntary basis. Not being covered by international databases and lack of IF seriously affects their visibility on the net. At the same time, mentally slave researchers in these countries are eager to publish their research work in well-known journals in the developed world. It has the disadvantage that their research is not known or is not accessible to local policy makers in the LMICs. Many policy makers are also not aware of what is being published by local journals and what its relevance is and importance with the result that local research is not put to proper use.

Journals have to play their role in advancing health science thereby contributing to national development. 
As such, it is extremely important that the editors follow an "Author Friendly Policy" but not to compromise on quality and appropriate peer review system. Sustainability of the journals mostly depends on good management policies. Governments, medical universities, regulatory bodies and professional societies in these LMICs should value the importance of local journals and make adequate investment in their sustainability. Medical journal editors in close cooperation with the authors should prepare press release for the media to highlight the findings of research published in scientific journals. They can also prepare policy briefs for policy makers and for the information of public.

Lastly, growing influence of Impact Factor has added to the worries of editors of small journals in LMICs. The Rejection or lack of response by US National Library of Medicine, which looks after indexing of journals in Medline, is continuous source of anger for many journals published from developing world. It is also interpreted by some as arrogance and cultural ignorance of the English speaking world.

We on our part from the platform of Pakistan Association of Medical Editors (PAME) in collaboration with the University of Health Sciences Lahore have started a Certificate Course in Medical Editing to train the editors so that it helps improve the standard of their publications ${ }^{4}$. Two batches have qualified so far and the third batch is under training. We are also starting a six month Online Course in Medical Editing and Journalism (CMEJ) from the platform of CORTEACH in collaboration with Pakistan Journal of Medical Sciences and Dow University of Health Sciences Karachi ${ }^{5}$. It will help those who cannot attend Face-to-Face courses at UHS, as well as some candidates from the neighboring countries and all these efforts are directed at training the editors thereby improving the standard of medical journals published from this part of the world. This will provide the researchers more opportunities to publish their research work in standard peer reviewed journals at a much lower cost and they will not have to wait for too long for publication.

\section{REFERENCES}

1. Huntley AC. Introducing dermatology online journal. Dermatol Online J. 1995;1 (1).

2. De Groote SL, Dorsch JL. Online journals: impact on print journal usage. Bull Med Libr Assoc. 2001; 89(4): 372-378.

3. Colorado State University. Online vs. Print [Internet]. 2010 [Accessed on July 27, 2021]. Available from: https://onlinevsprint.weebly.com/

4. Jawaid SA. Professional capacity building of researchers, health-care professionals and editors of biomedical journals in the Eastern Mediterranean Region. East Mediterr Health J. 2021;27(3):224-226.

5. CorTeach. Innovation, technology and learning at its best; 2021 [Accessed on July 27, 2021]. Available from: http://bit.ly/corteach-cmej 